hing"' can be atiapted 20 as to puitify the air of large buildings, without cusing draughi; by means of a fan and tank:

The figure (3) represents a diagram of the application of the "chemileal lung" to a theatre or any other large building. A is a rotary fan, ste in motion by an engine (not seen) which draws the vitiated atmosphere from the upper part of the building through the funnel-shaped office of B, placed in the ceiling where the air is hottest and most fdal, and forces it through the tank $\mathrm{c}$, which contains the chemical solution. The air, entirely deprived of all its impurities, passes out through the trunk $D$, at a temperature regulated at pleasure. By this arrangement, all draught is avoided, the pure air being either distributed by the branches opening out at the upper part of the several box or gallery floors of the building operated upon, or allowed to escape at once into the basement of the building, and so flood it with pure air cooled or warmed at pleasure.

The application of the principle, and the position and form of the apparatus, will necessarily depend on the structural features of the building itself.

The vitiated atmosphere may be forced by means of a fan either through a moist or dry chemical substance, at the rate of 5,000 to 16,000 feet or more per minute.

The advantages claimed for this scheme are :

1. Simplicity of adaptation, as the pipes may be carried outside the building like ordinary rain-water pipes, only larger.

2. Utilising the heat of the building, so that no warming apparatus is necessary, and the purified air can be supplied at -any required temperature.

3. Economy : the chemical agent when used up having a market value equal to, if not exceeding, its original cost.

4. That the air is perfectly pure, being deprived of all organic and chemical impurities incident to a crowded building.

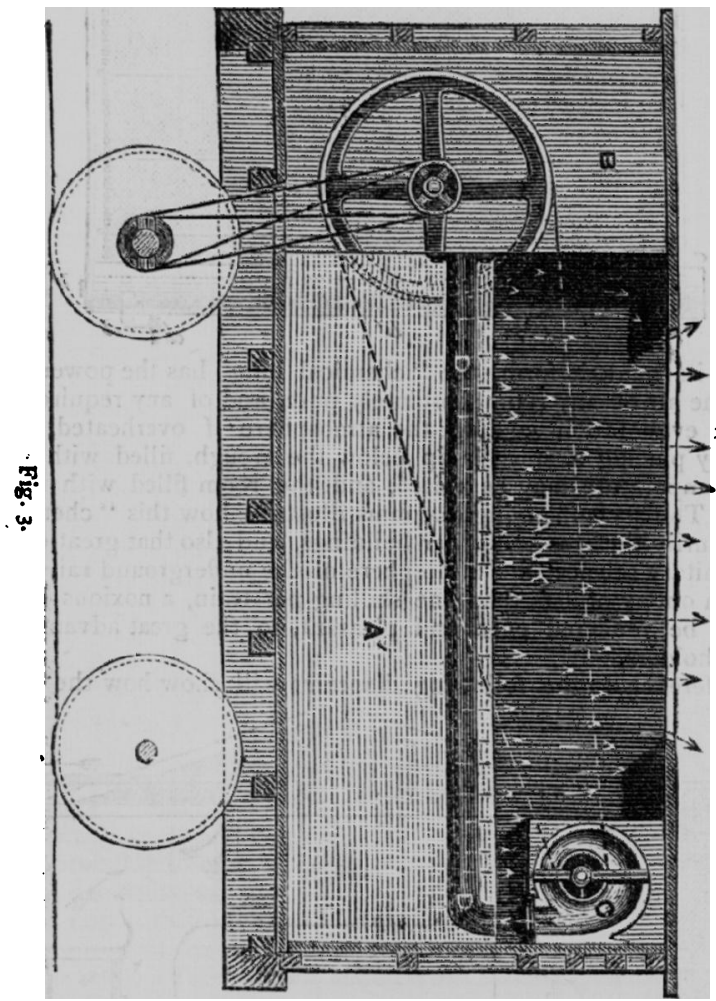

The above diagram illustrates one of the many means by which it is possible to render the atmosphere in an underground railway, or any similar tunnel, perfectly pure and wholesome, excepting for the carbonic oxide gas, which may be easily destroyed by heat, and, indeed, by proper care, need not exist at all. $A$ is a tank in a specially con. structed carriage, in which a fan, $\mathrm{C}$, is worked by the progress of the train. The tunnel-air is forced through the solution $A^{\prime}$ by means of the perforated pipe D D, passing out absolutely pure.

AN execution by the old fashioned method of beheading is reported from Copenhagen. It appears that the executioner bungled terribly, and aroused the indignation of the public.

\section{ON INVALID TRANSIT.}

BY RICHARD DAVY, M.B., F.R.C.S., Surgeon to the Westminster Hospital.

Since publishing my observations on invalid transit in 1876 , public attention has been directed more carefully to the absolute necessity of improvement in carriage building for such purposes; and my present object is, to again refer to the essential points demanded by the civil population: 1. For the comfort of the patient. 2. For the convenience of the surgeon in charge.

x. The Comfort of the Patient. - The necessity for conveying a pa. tient from one door to another, in any part of Great Britain, without any shift, must imply a van capable either of being drawn by a horse, or shunted on to a railway truck, or embarked on a steamer, and therefore able to resist inclement weather. or stand exposure; and carry on, so to speak, the wants of a sick-room during the journey. The utmost rest must be afforded to damaged structures; and this, I have always contended, is granted by the swing element in bed construction. The provision of plenty of room, air; light, etc.; stretcher mechanisms; and the easy entrance to and exit from the van, are necessary conditions for invalid comfort. The general appearance of the carriage should be quiet and unsuggestive; seclusion must be guaranteed at the option of the patient or surgeon; and the floor must be so constructed as to be easily cleaned without any bitch. The van must not exceed one-horse power; and must clear, on a truck, railway bridges and tunnels on the line.

2. The Convenience of the Surgeon in Charge. - Free communication must exist between the driver and the attendant inside. Space for chloroform, brandy, lint, bandages, and general provisions; also for sanitary utensils. All mechanisms - such as blinds, doors, windows-to be of the simplest and strongest kind. Within reasonable limits, the greatest amount of cubic capacity, and no fixtures capable of interfering with the rapid execution of surgical or nursing details. I have recently ordered Mr. John U. Burt, of 23, Swinton Street, King's Cross, to build a van for me embodying these conditions; and Mr. Burt has succeeded in every respect; and the van permits the carriage of one, or even, on an emergency, six invalids, one surgeon, and the driver.

Annexed are two drawings. Fig. I shows the general appearance of the van, with the door open (see also British Mrdical Journal,

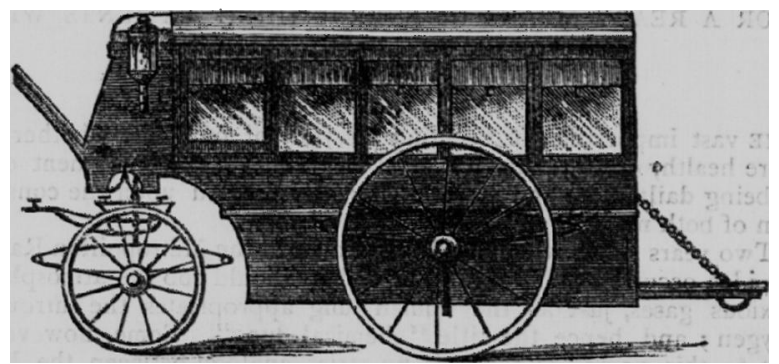

Fig. x.

October 28th, 1876). Fig. 2 exhibits an inside view; showing a ham-

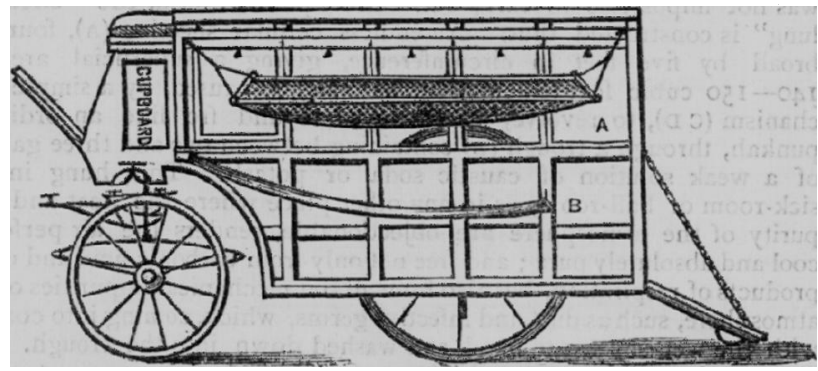

Fig. 2.

mock suspended (A); the line of two duck-litters (B), capable of easy removal; the cupboard for provisions, etc.; and the low-level foor. line, crank hind axle, suspended platform door, etc. The greatest inside capacity is: length, $9 \mathrm{ft}$; breadth, $4 \frac{1}{2} \mathrm{ft}$.; and height, 4 ft. 9 in.

By reason of the capacity of this van, invalids may be carried from spot to spot in their own beds, or on their own sofas. Chairs or camp. stools may be placed at discretion. At night, the inside is lit by a good hand-lamp. The carriage runs very easily, and offers a striking contrast in all respects to the intolerable four-wheeled cab. 
In coneluajop, I may state that the journeys I bave made in this van have practically been: very comfortable; that the railway rates are too dear, and the arrangements between so many different companie canse much complexity; but the future of invalid transit rests entirely with the British public, who will eventually decide on the best and most easy method of conveying sick and injured relatives. I shall be happy to exhibit my hammock, van, and stretchers to any professional man who may be interested in this subject; and arrangements may be made for the use of this van in cases of any description, excepting those of an infectious nature.

\section{DEVELOPMENT OF THE MAMMARY GLAND.*}

By ANTHONY A. BOWLBY, F.R.C.S.

Curator of the Museum of St. Bartholomew's Hospital.

Tris manner of the development of the breast has never until recent times been the subject of much controversy; the accounts in all works which described it as occurring by 2 process of involution of the cells of the epiblest, and the subsequent hollowing out of the ingrowth into a series of tubes, from which the acini were developed, were generally accepted without hesitation.

The chief authority for this description was Kölliker, and, in his last edition of his Entrvichlungsgeschichte, he depicts the origin of the mamma as being visible at the fifth month as an ingrowth of epithelium, from which by the seventh month ten to fifteen processes are protruded. Langer, while agreeing partly with Kölliker, maintained that, "the development of the mammary gland is bound up with the existence of a peculiar and independent body, in which the ducts develop without connection with the groove in the skin."

It was not, indeed, until Dr. Creighton, in his work on The Phy siology and Pathology of the Breast, threw doubts on the accuracy of previous observers, and suggested that conclusions had been arrived at after too scanty investigation, that the possibility of the origin of the mammary gland to a great extent from mesoblast was seriously entertained. The reputation of the author, the manifest care expended on his researches, and the arguments adduced, all combined to bring into great prominence the original conclusions contained in this work.

It is, perhaps, on this account the more remarkable that, although four years have passed 'since the publication of Dr. Creighton's book, no further investigations have'been made public in this country with a view either to confirm or to refute the accuracy of his statements.

Yet, considering the importance to pathology, as well as to descriptive anatomy and embryology, of an accurate knowledge of this subject, it appears to me that the matter ought not to be allowed to rest in its present unsettled state; and it is rather with a view of reawakening interest in it, than with any idea of settling the question offhand, that I have brought it under your notice.

The following is a brief statement of the opinions expressed by Dr. Creighton which are at variance with those of other authors. $\mathrm{He}_{\mathrm{e}}$ maintains that the epiblast is not the source from whence the acini are developed, and says, "The contention of the first part of this chapter is that the acini, or secreting structure of the breast, develop from a matrix-tissue at numerous scattered points or centres; that the matrix-tissue or embryonic cells is the same from which the fat surronoding the mamma develops; and that the mode of development of the acini is, for the individual cell, exactly the same process as in the development of the fat-lobules. The mammary gland would therefore be a further specialisation of fat-tissue, and a product of the mesoblast."......" The present description agrees with that of Goodsir in the impoitant point, that the development of acini is not by means of protrusians of the ducts so as to form infundibula or recesses at many points along their course, but that it is an interstitial development from the embryonic tissue that surrounds the ducts." (Page 99.)

As regards thedevelopment of the ducts, Dr. Creighton writes : "In the wedge-shaped body of embryonic tissue in the groin of a foetal guinea-pig less than half grown, but with the nipple already formed, there are seen, extending backwards from the nipple, certain narrow tracts of cells which are simply the embryonic cells of the part closely packed together. These tracts of closely packed cells form at various points throughout the embryonic mass independently of each other and no continuous extension of them can be traced from the nipple." ......" There is certainly "no evidence of a process of growth downwards from the rete mucosum under the nipple."....." The ducts are therefore held to be formed as aggregations of the embryonic cells of

Read in the. Section of Anatomy and Physiologg at the Annual Meeting of the British Médical it'sociation in Worcester, August 2882 . the matrix along certain predetermined lines; that preliminary point may be taken as established."

The conclusions of this inquiry are the following. $\quad 1$. The mam: mary acini of the guinea.pig develop at many separate points in a matrix-tissue; the embryonic cells from which they develop are of the same kind that give origin to the surrounding fat-tissue, and that the process of development of the mammary acini is step for step the same as that of the fat-lobules. 2. The ducts of the mamma develop from the same matrix-tissue by direct aggregation of the embryonic cells along predetermined lines; the ducts develop in the individual guinea-pig before the acini, whereas, in the phylogenetic succession, the ducts are a later acquisition; and this reversal of the order of acquisition of parts is in accordance with the principle

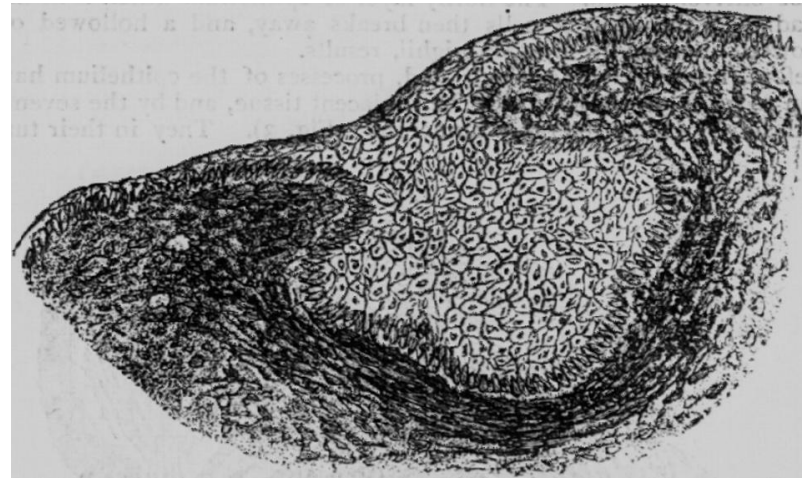

Fig. x.-Section of the mammary gland of a foetus in the fifth month, showing the ingrowth of the epithelitum into the subjacent tissues.

stated by Mr. Herbert Spencer that, under certain circumstances, the direct mode of development tends to be substituted for the indirect."

It is needless for me to summarise further Dr. Creighton's opinions; they are expressed with admirable clearness; hut it deserves to be remarked at the outset that the animals selected were mainly either kittens or guinea-pigs, while the conclusions arrived at as a result of his observations, and of a consideration of the types of gland-development in other animals, are equally applied to the human mamma (see pages $13^{6}$ and 137 ); indeed, had it been otherwise, the work would have lost much of its interest. My omn investigations have

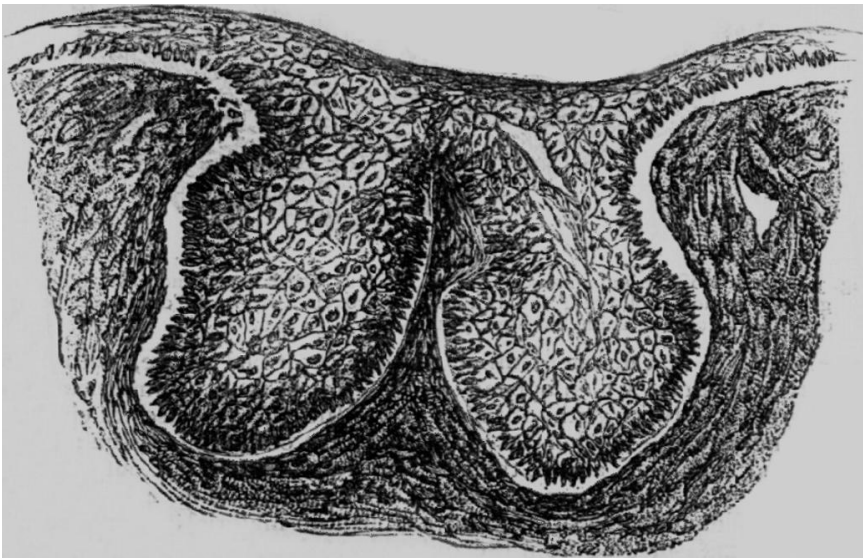

Fig 2.-Section of the mammary gland of a foetus at the beginning of the sixth month The ingrowth is larger, and the bridge of epithelium yet intact.

been conducted entirely on the human subject, the material at my disposal consusted of thirty-four breasts taken from foetuses whose age varied from four months of intra-uterine life to one month after birth. Sections were cut of the whole of these, and between 200 and 300 were mounted and examined; those which I show you to-day have been selected as most suitable for my purpose, and most of the conclusions I shall ask you to accept, may either be confirmed or negatived by an examination of them.

The age given must be taken as to a great extent approximate. I judeed of it by the most ordinary and ttustworthy. methods. The eract time at which the first rudiment of the mamma becomes evident, 